\title{
The Investigation of Optimizing Leaching Efficiency of Al in Secondary Aluminum Dross via Pretreatment Operations
}

\author{
Haigang Feng ${ }^{1}$, Guofan Zhang ${ }^{1, *}$, Qun Yang ${ }^{2}$, Luobing Xun ${ }^{1}$, Siyuan Zhen ${ }^{1}$ and Dezhi Liu ${ }^{1}$ \\ 1 School of Minerals Processing and Bioengineer, Central South University, Changsha 410083, China; \\ 185611050@csu.edu.cn (H.F.); $185611056 @ c s u . e d u . c n$ (L.X.); zhensiyuan@csu.edu.cn (S.Z.); \\ di_li@163.com (D.L.) \\ 2 Chongqing Academy of Metrology and Quality Inspection, Chongqing 400000, China; 165611076@csu.edu.cn \\ * Correspondence: 129183@csu.edu.cn; Tel.: +86-1397-510-9810
}

Received: 10 September 2020; Accepted: 6 October 2020; Published: 9 October 2020

\begin{abstract}
Secondary aluminum dross (SAD) is an inevitable by-product from the secondary aluminum industry and has caused serious environmental issues. In this study, the effect of pretreatment operations on the subsequent acid leaching operation was studied by process mineralogy, a series of leaching experiments, XRD, and SEM. Leaching results showed that the leaching efficiency of $\mathrm{Al}$ in direct acid leaching was only $22.99 \%$. Process mineralogy showed the complex intertexture and continuous network structure in the SAD. Pretreatment operations were extremely efficient in destroying the structure by physical and chemical interaction. Interestingly, by adding the grinding and water leaching operations, the leaching efficiency of total aluminum in the SAD reached approximately $28.70 \%$. XRD results showed that nearly all metallic $\mathrm{Al}, \mathrm{AlN}$, and partial $\mathrm{Al}_{2} \mathrm{O}_{3}$ were leached by grinding-water leaching-acid leaching. The scanning electron micrographs showed that the residue particles mainly included some insoluble components and had a smooth surface.
\end{abstract}

Keywords: secondary aluminum dross; process mineralogy; ball grinding; water leaching

\section{Introduction}

Secondary aluminum dross (SAD), which forms during the aluminum scrap/dross melting processes, is an inevitable by-product from the secondary aluminum industry [1,2]. Metal aluminum can be recycled almost completely without loss of quality from the aluminum scrap/dross, and the amount of this scrap has been increasing rapidly. The production of secondary aluminum not only saves $95 \%$ of the energy but also avoids approximately $95 \%$ of the emissions of noxious gas compared with the primary aluminum production from bauxite [2-4]. Thus, the secondary aluminum industry has been booming in the past few years.

With the prosperity of the secondary aluminum industry, more than one million tons of SAD are produced every year worldwide [5]. The SAD typically contains aluminum (Al) metal, aluminum oxide $\left(\mathrm{Al}_{2} \mathrm{O}_{3}\right)$, aluminum nitride (AlN), halite, sylvite, and other contaminants, and these compounds are harmful to the environment and difficult to recover. The current treatment of the SAD cannot balance the relationship between economy and the environment. Approximately $95 \%$ of the SAD has been stacked and landfilled [6,7]. The leachability of the landfilled SAD normally leads to the leaching of toxic metal ions into ground water, and the high reactivity of the SAD with water can result in the formation of toxic, explosive, and poisonous odorous gases, such as $\mathrm{NH}_{3}, \mathrm{CH}_{4}, \mathrm{PH}_{3}$, $\mathrm{H}_{2}$, and $\mathrm{H}_{2} \mathrm{~S}$ [8-10]. The toxic metal ions and gaseous emissions from the landfilled SAD is a great environmental concern [8-11]. Therefore, finding a feasible process for treating SAD is imperative. 
The chemical and mineral compositions of SAD in different regions vary greatly because of the diversity of the scrap feed, which is a complex combination of all types of aluminum scraps collected [12,13]. Given the complex compounds and lower Al metal content of the SAD, the hydrometallurgical process is preferred than the pyrometallurgical method in treating the SAD [14]. The former process is sensitive to some impurities in the SAD, necessitating pretreatment before acid/alkaline leaching. The traditional operations in pretreating SAD consist of ball grinding and water leaching. Nevertheless, the previous researchers just used ball milling and water leaching to recover the Al metal and dissolve the salt $[15,16]$. The researchers neither studied the comprehensive influences of ball milling and water leaching on the subsequent acid/alkaline leaching operation, nor analyzed the mechanism of the operations.

Ball milling plays an important role in recovering Al metal from the SAD. Given the higher ductility and viscosity of the $\mathrm{Al}$ metal compared with the other components in the SAD, the $\mathrm{Al}$ metal will become increasingly bigger, while the other components will become smaller during the ball-milling operation [17]. Türk et al. [18] studied the effect of particle size on the efficiency of extracting Al. The results showed that ball milling could increase the mechanical activation of the aluminum dross. David et al. [19] investigated the influence of high-speed ball milling on the superficial area of the Al particle in aluminum dross. The results showed that ball milling could not only decrease the particle size and increase the surface area of the aluminum dross but also produce a disordered structure by the agglomeration of microparticles. Thus, ball milling contributed to a reduced reaction temperature and higher chemical reactivity. Moreover, the existence of the hydroxide or oxide protective film on the Al particle surface could be destroyed by ball milling. Nhi et al. [20] found that the milling speed had a great influence on the leaching behavior of silica and the oxides of $\mathrm{Ca}, \mathrm{Fe}, \mathrm{Mg}$, and $\mathrm{Ti}$ in the aluminum dross.

Water leaching is indispensable for high-pressure leaching, because soluble salts have a great effect on the leaching of $\mathrm{Al}$, and some compounds in the SAD can be decomposed by reacting with water to emit explosive gases during digestion [21]. Bruckard et al. [21] determined the feasibility of extracting soluble salts and decomposing aluminum nitrides and carbides in the SAD by water leaching. The results showed that $86-89 \%$ of chloride, $54-58 \%$ of sodium, and $37-43 \%$ of potassium were dissolved during water leaching at $25^{\circ} \mathrm{C}$, whereas only small amounts of the other elements were extracted during the process. Tsakiridis et al. [22] proved that $80 \%$ of sodium and $85 \%$ of potassium was removed during water leaching at $90{ }^{\circ} \mathrm{C}$, and the yield of black dross was only $89 \%$ after water leaching.

The aforementioned studies on ball milling and water leaching have mainly focused on the impact of the operation itself to the SAD and ignored the impact on subsequent acid/alkaline leaching operations. In this paper, the study started from the mineralogical analysis of the SAD, and the results were used to select the appropriate pretreatment operations. A series of comparation experiments were conducted to verify the effect of the pretreatment operations. In addition, the role of pretreatment operations in the leaching of the SAD was investigated through XRD and SEM.

\section{Materials and Methods}

\subsection{Materials}

\subsubsection{SAD}

The SAD sample was supplied by an aluminum company located in Kunming, Yunnan Province, China. The SAD was deep gray in color and smelled pungent, because ammonia is released when the SAD reacts with water in a humid environment. According to the results of the chemical and phase analysis shown in Figures S1 and S2, which were also reported in previous studies [23,24], Al and O compose $77.44 \%(\mathrm{wt})$ of the total elements, which mainly exist in the $\mathrm{Al}$ phase, alumina (including $\alpha$-alumina, $\beta$-alumina, and $\gamma$-alumina), $\mathrm{NaAl}_{11} \mathrm{O}_{17}$, and $\mathrm{MgAl}_{2} \mathrm{O}_{4}$. In addition, $\mathrm{Na}, \mathrm{K}$, and $\mathrm{Cl}$ compose $14.23 \%$, which are in the salt phase, such as $\mathrm{NaCl}$ and $\mathrm{KCl}$. After repeating the leaching operations with the alkaline solution, the total quantity of AlN in the SAD is $14.38 \%$. Thus, the calculated $\mathrm{Al}$ 
element in AlN accounts for $19.35 \%$ of the total Al element in the SAD. The SAD contains a small quantity of the impurity elements (e.g., F, Mg, $\mathrm{Si}, \mathrm{Fe}, \mathrm{Ga}, \mathrm{Ti}$, and V).

The results in the analysis of the grain size and metal $\mathrm{Al}$ of the SAD are listed in Table $1 . \mathrm{The} \mathrm{Al}$ grade of the initial SAD is $3.58 \%$. The yield of each size fraction is evenly distributed, but the grade of Al varies greatly. The smaller the particle size is, the lower the grade will be. The metal Al grade of $(0.25-0.45 \mathrm{~mm})$ size fraction reaches up to $15.26 \%$. However, the grade of the particle size fraction below $0.076 \mathrm{~mm}$ is only $1.31 \%$. Thus, the metal $\mathrm{Al}$ is mainly distributed with a coarse grain size.

Table 1. Grain-size and metal aluminum analysis of the secondary aluminum dross (SAD).

\begin{tabular}{cccc}
\hline Grain-Size (mm) & Yield (\%) & Aluminum Grade (\%) & Aluminum Distribution (\%) \\
\hline $0.25-0.45$ & 6.65 & 15.26 & 26.63 \\
\hline $0.15-0.25$ & 21.50 & 5.72 & 35.18 \\
\hline $0.10-0.15$ & 29.71 & 2.23 & 18.95 \\
\hline $0.076-0.10$ & 24.05 & 1.81 & 12.45 \\
\hline $0-0.076$ & 18.08 & 1.31 & 6.78 \\
\hline Initial SAD & 100.00 & 3.58 & 100.00 \\
\hline
\end{tabular}

\subsubsection{Chemical Reagents}

Hydrochloric acid ( $\mathrm{HCl}, 37 \%)$, ammonia (25\%), and boracic acid (99\% purity) were purchased from Hunan Huihong Reagent Co., Ltd. (Changsha, China). All chemicals were used without any additional purification. Deionized water was used at all stages of the experiment unless otherwise stated.

\subsection{Methods}

\subsubsection{Grinding operation}

A conical ball mill of XMQ- $\Phi 240 \times 90$ (Wuhan Prospecting Machinery Factory, Wuhan, China) with a rotational speed of up to $96 \mathrm{rpm}$ was employed for the grinding operation. The grinding operation was performed as follows. SAD (500 g) and deionized water $(300 \mathrm{~mL})$ were mixed to form a slurry with $60 \%$ concentration. The mixture was added into the ball mill with $7.6 \mathrm{~kg}$ of iron balls and then milled for 2.5, 5, 7.5, 10, and $20 \mathrm{~min}$ at $96 \mathrm{rpm}$. Then, the slurry in the ball was rinsed using $920 \mathrm{~mL}$ of the deionized water, which needed to be strictly controlled so that the liquid-solid ratio of the subsequent leaching operation was $50 \mathrm{~mL} / 20 \mathrm{~g}$.

\subsubsection{Leaching Operation}

The schematic of the leaching device is presented in Figure S2, which was previously reported [23,24]. Each experiment for the leaching of the SAD was performed in a $250 \mathrm{~mL}$ conical flask, which was placed in an oil bath and heated at a fixed test temperature. For each leaching operation, $50 \mathrm{~mL}$ of the corresponding leaching solution was first added to the conical flask, and then the Electro-Thermostatic water bath was turned on to heat the solution to the required temperature before $20 \mathrm{~g}$ of the solid sample was added. Then, the slurry was agitated at different temperatures and time. Finally, the slurry was filtered with a Buchner funnel to collect the pregnant liquor to measure the amount of ammonia nitrogen and the concentration of Al. The leaching residues were dried and weighed.

\subsection{Detection and Analysis Methods}

The total aluminum concentration in the leaching solution was determined by inductively coupled plasma optical emission spectrometer (ICAP7400 Radial, Thermo Fisher Scientific company, Waltham, MA, USA) to calculate the leaching efficiency of total aluminum. The detailed analysis conditions 
include wavelength range: $166-847 \mathrm{~nm}$; optical system: constant temperature drive type; light chamber temperature: precise constant temperature $38^{\circ} \mathrm{C} \pm 0.1^{\circ} \mathrm{C}$; optical resolution: $\leq 0.007 \mathrm{~nm}$ at $200 \mathrm{~nm}$, $0.014 \mathrm{~nm}$ at $400 \mathrm{~nm}, 0.021 \mathrm{~nm}$ at $600 \mathrm{~nm}$; plasma observation method: vertical observation of vertical flame. Nessler's Reagent Spectrophotometry (HJ535-2009) was used to determine the ammonia nitrogen in the leaching solution. The specific test method and principle were introduced in our previous paper [23].

After the initial sample was received from Kunming, Yunnan Province, China, the samples were first mixed several times to make the components uniform. Then, the imbedded characteristics of the initial SAD were examined by using a polarized light microscope (Leica DMLA, Wetzlar, Germany), and the grain size was analyzed by using a series of sieves with different apertures. After the initial SAD was ground with an agate mortar to make particles with size $\leq 44 \mu \mathrm{m}$, the elemental and mineralogical analyses were performed by X-ray fluorescence (XRF, Axiosm AX, Panalytical. B. V, Almelo, The Netherlands) and X-ray diffraction (XRD, X-Pert ${ }^{3}$ Powder, Panalytical. B. V, Almelo, The Netherlands), respectively. Finally, the morphology of the SAD was explored by scanning electron microscopy (SEM; Phenom ProX scanning electron microscope). To explore the variation in the leaching residues compared with the initial SAD, all aforementioned analyses, except the measurements from the polarized light microscope and $\mathrm{XRF}$, were also used to determine the characteristic of the leaching residues.

\section{Results and Discussion}

\subsection{Direct Acid Leaching Process}

Metal $\mathrm{Al}$ and some $\mathrm{Al}$ compounds in the SAD are amphoteric, which can be dissolved in either acidic or alkaline solutions. The acid solution has a strong reaction ability and can leach various metal oxides, such as magnesium oxide, ferric oxide, and calcium oxide from the SAD. Thus, the acid leaching residue almost does not contain metal impurities. In contrast, the alkaline solution can just leach $\mathrm{SiO}_{2}$ from $\mathrm{SAD}$, except $\mathrm{Al}$ compounds, and a relatively pure leaching solution can be obtained. $\mathrm{HCl}$, which is generated as a by-product in many chemical industries [25,26], is a versatile acid and readily available. In addition, to obtain a relatively pure leaching residue for refractory and building materials, $\mathrm{HCl}$ has been selected as the leaching agent of the SAD. The reaction in the leaching solution is as follows:

$$
\begin{gathered}
\mathrm{Al}(\mathrm{s})+3 \mathrm{HCl}(\mathrm{aq}) \rightarrow \mathrm{AlCl}_{3}(\mathrm{aq})+1.5 \mathrm{H}_{2}(\mathrm{~g}) \\
\mathrm{AlN}(\mathrm{s})+4 \mathrm{HCl}(\mathrm{aq}) \rightarrow \mathrm{AlCl}_{3}(\mathrm{aq})+\mathrm{NH}_{4} \mathrm{Cl}(\mathrm{aq}) \\
\mathrm{Al}_{2} \mathrm{O}_{3}(\mathrm{~s})+6 \mathrm{HCl}(\mathrm{aq}) \rightarrow 2 \mathrm{AlCl}_{3}(\mathrm{aq})+3 \mathrm{H}_{2} \mathrm{O} \\
\mathrm{Fe}_{2} \mathrm{O}_{3}(\mathrm{~s})+6 \mathrm{HCl}(\mathrm{aq}) \rightarrow 2 \mathrm{FeCl}_{3}(\mathrm{aq})+3 \mathrm{H}_{2} \mathrm{O} \\
\mathrm{CaO}(\mathrm{s})+2 \mathrm{HCl}(\mathrm{aq}) \rightarrow \mathrm{CaCl}_{2}(\mathrm{aq})+\mathrm{H}_{2} \mathrm{O} \\
\mathrm{MgO}(\mathrm{s})+2 \mathrm{HCl}(\mathrm{aq}) \rightarrow \mathrm{MgCl}_{2}(\mathrm{aq})+\mathrm{H}_{2} \mathrm{O}
\end{gathered}
$$

In the $\mathrm{HCl}$ solution, corundum and magnesia-alumina spinel are sufficiently stable and insoluble. Thus, the efficiency of leaching the total $\mathrm{Al}$ is the sum of the efficiencies in extracting $\mathrm{Al}, \mathrm{AlN}$, and activated- $\mathrm{Al}_{2} \mathrm{O}_{3}$. To determine the contribution of each $\mathrm{Al}$ component to the leaching rate of the total $\mathrm{Al}$, the decomposition rate of $\mathrm{AlN}$ obtained by the analysis of ammonia nitrogen in the leachate should be known when the efficiency in leaching $\mathrm{Al}$ and activated- $\mathrm{Al}_{2} \mathrm{O}_{3}$ is difficult to detect.

Prior to the optimization of the leaching temperature and time, a series of experiments were conducted to determine the optimal acid concentration ( $6 \mathrm{~mol} / \mathrm{L})$, liquid-to-solid ratio (L/S) $(50 \mathrm{~mL} / 20 \mathrm{~g})$, and stirring speed (300 rpm). The results are shown in Figures S3-S5. The optimal conditions were used in all subsequent tests. Figure 1 exhibits the variation of the decomposition of AlN at different temperatures. As shown in Figure 1, as the leaching time progresses, the decomposition rate of AlN 
increases rapidly in the first $60 \mathrm{~min}$. When leaching time is higher than $60 \mathrm{~min}$, the decomposition rates of AlN at $298.15 \mathrm{~K}$ and $348.15 \mathrm{~K}$ are basically unchanged, demonstrating that the leaching process has reached equilibrium. However, at $323.15 \mathrm{~K}$, the curve keeps an almost average rate of increase over time. According to a previous study [24], the high activation energy (40.93 kJ/mol) of the reaction between $\mathrm{AlN}$ and $\mathrm{HCl}$ is the main reason for the overall trend of the AlN decomposition curve. In addition, the highest decomposition ratio of $\mathrm{AlN}$ is approximately $42.5 \%$ in the $\mathrm{HCl}$ solution at $348.15 \mathrm{~K}$.

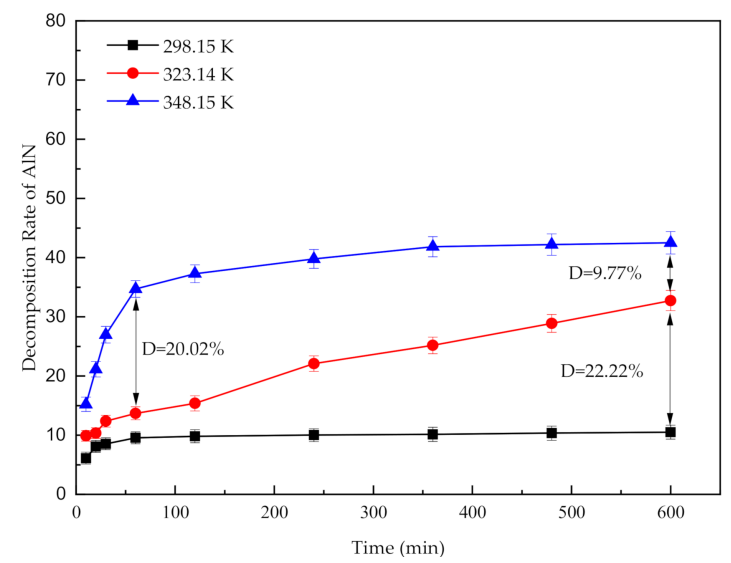

Figure 1. Effect of acid leaching temperature on the decomposition of AlN at different leaching times.

Figure 2 presents the effects of temperature on the efficiency of leaching total $\mathrm{Al}$ at different times. With the increase in temperature and extension of leaching time, the efficiency of leaching the total $\mathrm{Al}$ shows a similar trend with the decomposition rate of AIN. This result indicates that the extraction of AlN accounts for a large proportion of the leaching efficiency of the total Al. The higher the temperature is, the higher the efficiency of leaching the total $\mathrm{Al}$ will be. The results indicate that when the leaching temperature is increased from $298.15 \mathrm{~K}$ to $348.15 \mathrm{~K}$, the efficiency of leaching the total Al rises from $14 \%$ to $22.99 \%$. To determine the reason for the low leaching efficiency, the inlay structure and the leaching mechanism of all components in the SAD need to be explored. Thus, the process mineralogy of the SAD was investigated.

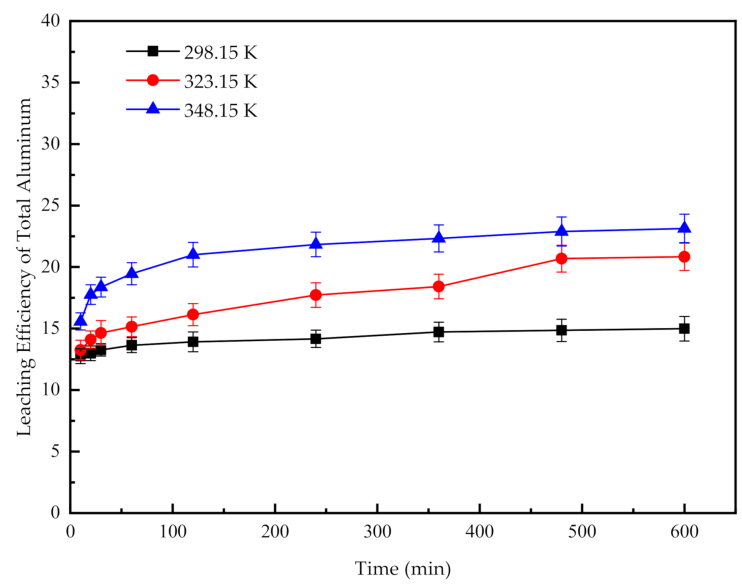

Figure 2. Effect of acid leaching temperature on the leaching efficiency of the total $\mathrm{Al}$ at different leaching times.

\subsection{Investigation of the Process Mineralogy of the $S A D$}

According to the XRD pattern of the SAD in Figure S1 [24], the SAD mainly constitutes seven phases, namely, metallic $\mathrm{Al}, \mathrm{NaCl}, \mathrm{AlN}$, corundum ( $\alpha$-alumina), $\beta$-alumina $\left(\mathrm{NaAl}_{11} \mathrm{O}_{17}\right)$, magnesia-alumina spinel $\left(\mathrm{MgAl}_{2} \mathrm{O}_{4}\right)$, and silicon dioxide $\left(\mathrm{SiO}_{2}\right)$. To explore the complex inlay structure of these phases in 
the $\mathrm{SAD}$, the process mineralogy of the SAD, which is usually used to analyze the inlay structure of ore in nature before the beneficiation process, was performed. The specific inlay structure of SAD is shown in Figure 3.
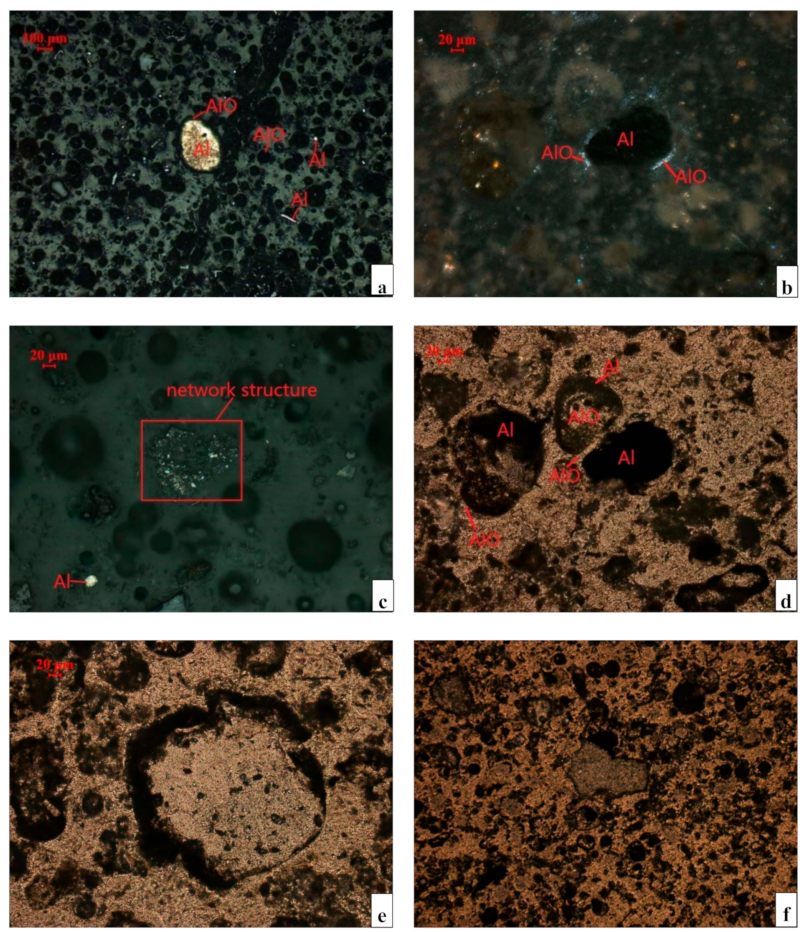

Figure 3. Microstructures of the SAD as viewed through an ore microscope. (a) Metallic $\mathrm{Al}$ in the form of pellets and flakes in the reflected light. (b) Sphere metal Al in orthogonal polarization. (c) Agglomerates or continuous particles of metal $\mathrm{Al}$ in the reflected light. (d) Embedded relationship between the metal $\mathrm{Al}$ and alumina in single polarization. (e) Fine alumina in single polarization. (f) Flake alumina in single polarization. Note: Al metal aluminum; AlO-alumina ( $\beta$-alumina, $\alpha$-alumina, and $\gamma$-alumina).

The microstructures of the SAD observed using an ore microscope are presented in Figure 3. Figure 3a shows that the metal $\mathrm{Al}$ in the $\mathrm{SAD}$, with size ranging from $20 \mu \mathrm{m}$ to $200 \mu \mathrm{m}$, is mainly round and covered with inhomogeneous oxide layers. The layers consist of fine alumina particles and are $2-20 \mu \mathrm{m}$ thick (Figure $3 \mathrm{~b}$ ). The alumina mainly exists as fine particles with the size range of 2-200 $\mu \mathrm{m}$ (Figure 3e) and a small amount as flakes (Figure 3f). The complex interwoven structure between the Al metal and alumina is shown in Figure 3d. The alumina layer covers the Al metal, which contains alumina particles. The encapsulated metallic $\mathrm{Al}$ cannot be in contact with the acid leachate to be extracted, unless the superficial alumina is destroyed or dissolved in the leachate. However, the superficial alumina ( $\alpha$-alumina) is primarily stable and insoluble in the acid solution. The best way to release the metallic $\mathrm{Al}$ is to destroy the superficial layer by the external mechanical forces from ball milling.

Figure $3 c$ presents that part of the metallic $\mathrm{Al}$, which is generally smaller than $5 \mu \mathrm{m}$, agglomerates or bonds with fine particles, such as $\mathrm{Al}_{2} \mathrm{O}_{3}, \mathrm{AlN}$, and aluminate, to form a continuous network structure with particle size ranging from $30 \mu \mathrm{m}$ to $200 \mu \mathrm{m}$. In a previous study [23,24], the degree of decomposition of AlN in the aqueous solution is better than that in $\mathrm{HCl}$. This result indicates that the AlN in a continuous network structure can decompose more completely by water leaching. The $\mathrm{Al}(\mathrm{OH})_{3}$ formed by the hydrolysis of $\mathrm{AlN}$ is very easy to dissolve in $\mathrm{HCl}$ solution, which can produce small bores to destroy the structure and release more soluble $\mathrm{Al}$ components. Therefore, the efficiency of leaching the total $\mathrm{Al}$ can be optimized by the water leaching operation.

The SAD is formed during the $\mathrm{Al}$ scrap/dross melting processes. Thus, the seven phases of the $\mathrm{SAD}$ are tightly bound in a very complex structure, which can be confirmed by the analysis of process 
mineralogy. The interwoven and continuous network structures severely hinder the contact between the soluble $\mathrm{Al}$ components and the leachate and significantly affect the efficiency of leaching the total Al. To destroy the compact structure to increase the superficial area and release the soluble aluminum components [26], pretreatment is extremely essential. Moreover, the mechanical activation of SAD is greatly improved by ball milling, which increases the rate of leaching the SAD [18]. Water leaching can remove the majority of most soluble salts to enhance the efficiency of leaching the total $\mathrm{Al}$ and decompose harmful materials that can react with water to emit some pungent explosive gas [21].

\subsection{Effects of the Pretreatment Operation on Acid Leaching}

\subsubsection{Effect of Ball-Grinding Operation}

Mechanical ball milling refers to a process that uses mechanical forces, such as grinding, impact, and shearing, to promote the physical and chemical changes in substances. Changes in the SAD caused by ball milling includes the reduction of particle size, more cracks, increase in the superficial area, and removal of pellumina on the metallic Al surface. Figure 4 indicates the effect of grinding time on the particle size of the SAD. Figure 4a shows that the particle size of the SAD decreases sharply at the beginning, the proportion of the particle size fraction below $76 \mu \mathrm{m}$ in the SAD increases from $18.08 \%$ to $80 \%$ after grinding for $2.5 \mathrm{~min}$. Thereafter, the particle size decreases steadily at a slower speed, and the particle size fraction below $76 \mu \mathrm{m}$ fraction accounts for $96 \%$ after $20 \mathrm{~min}$ of grinding. As the particle size decreases, the complex inlay structure of SAD is destroyed, and the mechanical activation of the SAD system is promoted [18].

Considering simultaneously the loss of electric energy and the grinding effect, $2.5 \mathrm{~min}$ was selected as the optimal milling time to conduct the subsequent experiments, and $348.15 \mathrm{~K}$ was chosen as the optimal leaching temperature. Figure $4 \mathrm{~b}$ presents the effect of grinding on the decomposition rate of AlN at $348.15 \mathrm{~K}$ in the $\mathrm{HCl}$ solution. As shown in Figure $4 \mathrm{~b}$, regardless of whether a ball milling operation is performed, the variations of the curves are similar. The decomposition rate of AlN increases sharply in the first $120 \mathrm{~min}$ and continues to ascend slightly thereafter. At $373.15 \mathrm{~K}$, the final decomposition rate of AlN reaches $46 \%$ after grinding, which is only $4 \%$ higher than that without the grinding operation. The decomposition of AlN is suppressed to some extent due to the nature of $\mathrm{HCl}$. Thus, the grinding operation cannot improve obviously the decomposition rate of AlN. However, the reaction rate significantly increases with the improvement of the mechanical activation of the SAD system.

The effect of grinding on the efficiency of leaching the total $\mathrm{Al}$ at $348.15 \mathrm{~K}$ in the $\mathrm{HCl}$ solution is shown in Figure 4c. The grinding operation dramatically improves the efficiency of leaching the total $\mathrm{Al}$, which increases initially and then remains at equilibrium in the two curves. By comparing the two final equilibrium values, the efficiency of leaching the total $\mathrm{Al}$ after grinding is $5.43 \%$ higher than that without grinding. The increase in this efficiency is markedly higher than the decomposition of AlN, because the Al element in AlN only accounts for $19.35 \%$ of the total Al element in the SAD. Thus, the grinding operation mainly improves the efficiency of leaching metallic $\mathrm{Al}$ and alumina in the SAD by exposing more metallic $\mathrm{Al}$ particles and increasing the mechanical activation of the SAD system. 


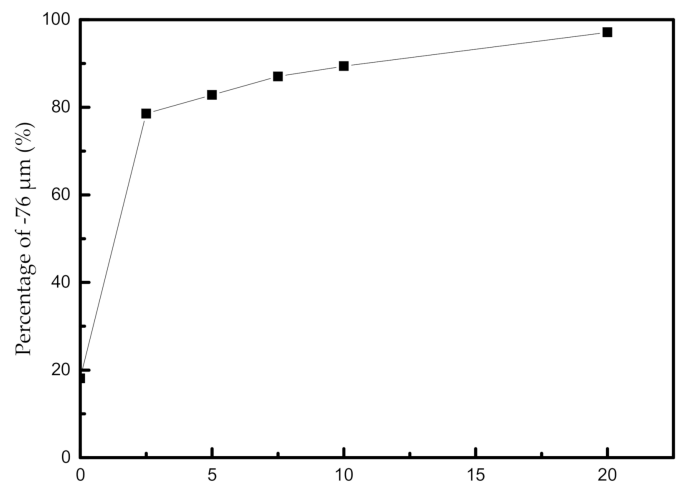

(a) Time (min)

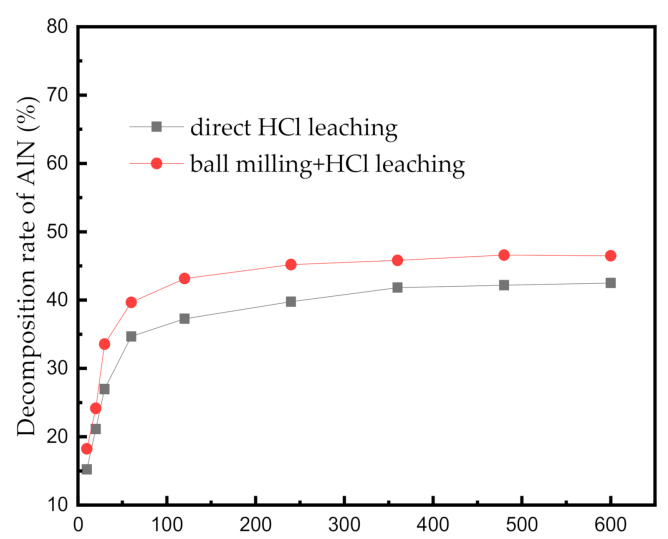

(b) Time (min)

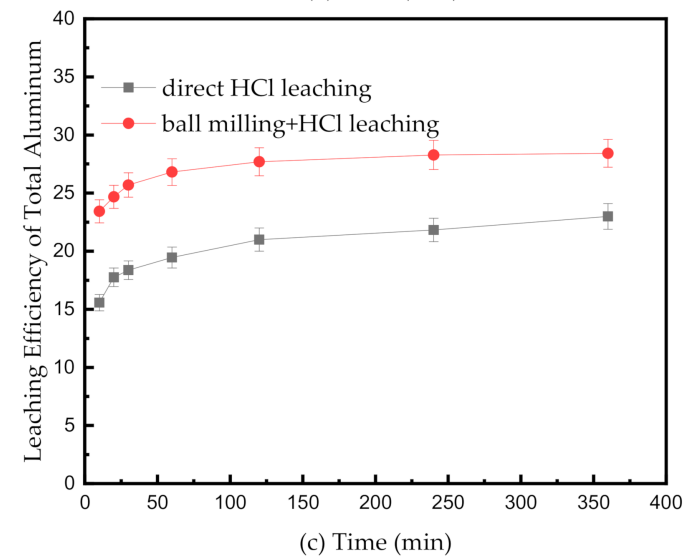

Figure 4. (a) Effect of grinding time on the particle size of the SAD; (b) effect of different operations on the decomposition rate of aluminum nitride at $373.15 \mathrm{~K}$ in the $\mathrm{HCl}$ solution; (c) effect of different operations on the efficiency of leaching the total $\mathrm{Al}$ at $373.15 \mathrm{~K}$ in the $\mathrm{HCl}$ solution.

\subsubsection{Effect of Water Leaching Operation}

Water leaching is the conventional pretreatment of the SAD to remove the Na and $\mathrm{K}$ salts. Bruckard et al. [21] proved that soluble salts had a great effect on the leaching of the total $\mathrm{Al}$ in the SAD. Thus, to some extent, water leaching can improve the efficiency of leaching the total Al. However, the feasibility of determining the efficiency of leaching the total $\mathrm{Al}$ on the basis of a noncompact structure created by the reaction between water and AlN is rarely studied. The AlN in the SAD can be hydrolyzed in water leaching and turn to $\mathrm{Al}(\mathrm{OH})_{3}$ and $\mathrm{NH}_{3}$. Then, $\mathrm{NH}_{3}$ dissolves in water, increasing the solution $\mathrm{pH}$, which enhances the reactivity of $\mathrm{Al}_{1} \mathrm{Al}_{2} \mathrm{O}_{3}$, and $\mathrm{AlN}$. The reactions in the water leaching operation are as follows:

$$
\mathrm{AlN}(\mathrm{s})+4 \mathrm{H}_{2} \mathrm{O} \rightarrow \mathrm{Al}(\mathrm{OH})_{3}(\mathrm{~s})+\mathrm{NH}_{3} \cdot \mathrm{H}_{2} \mathrm{O}(\mathrm{aq})
$$




$$
\begin{aligned}
2 \mathrm{Al}(\mathrm{s})+6 \mathrm{H}_{2} \mathrm{O} & \rightarrow 2 \mathrm{Al}(\mathrm{OH})_{3}(\mathrm{~s})+3 \mathrm{H}_{2}(\mathrm{~g}) \\
\mathrm{NaCl} & \rightarrow \mathrm{Na}^{+}+\mathrm{Cl}^{-} \\
\mathrm{KCl} & \rightarrow \mathrm{K}^{+}+\mathrm{Cl}^{-}
\end{aligned}
$$

In Figure S6 [23], the hydrolysis of AlN in the SAD results in the 59\% and $41 \%$ decomposition ratio of AlN at $348.15 \mathrm{~K}$ and $323.15 \mathrm{~K}$, respectively. Approximately $67 \%$ of AlN is decomposed after reacting with water for $240 \mathrm{~min}$ at $375.15 \mathrm{~K}$, which is the highest decomposition rate of AlN. By comparing the optimal decomposition rates of $\mathrm{AlN}$ in water and $\mathrm{HCl}, \mathrm{AlN}$ reacts more easily with water than with $\mathrm{HCl}$ [24]. Moreover, the product of hydrolysis is more soluble than AlN in $\mathrm{HCl}$. Thus, the decomposition rate of AlN is promoted by water leaching.

Figure S7 presents the effect of the water leaching temperature on the efficiency of leaching the total $\mathrm{Al}$ at different times. The efficiency of leaching the total $\mathrm{Al}$ in the SAD is almost maintained at zero in the different temperatures during the water leaching process. The Al element in AlN and Al metal in the SAD are transformed into $\mathrm{Al}(\mathrm{OH})_{3}$, which is insoluble in water [23]. The newly formed $\mathrm{Al}(\mathrm{OH})_{3}$ dissolves more easily than AIN in subsequent acid leaching operations, which provides favorable conditions for the leaching of $\mathrm{Al}$ in the SAD [24].

Figure 5 exhibits the effect of different operations on the efficiency of leaching the total $\mathrm{Al}$ at $348.15 \mathrm{~K}$ at different leaching times. The efficiency with water leaching is markedly higher than that in leaching with acid only in the first $60 \mathrm{~min}$, and the gap gradually decreases thereafter. When the two curves in Figure 5 reach equilibrium, the efficiencies of leaching the total $\mathrm{Al}$ are $22.99 \%$ and $24.34 \%$ in the two different operations, respectively. Water leaching can significantly increase the reaction rate of $\mathrm{Al}$ leaching based on the noncompact structure created by the reaction between water and AlN. However, the leaching efficiency of total $\mathrm{Al}$ only increases slightly because of the large particle of the SAD and the low mechanical activation of the SAD system.

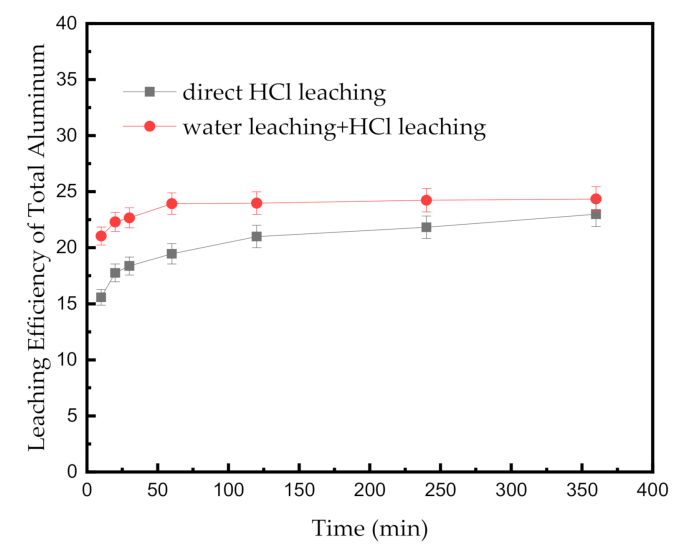

Figure 5. Effect of different operations on the leaching efficiency of total $\mathrm{Al}$ at $348.15 \mathrm{~K}$ at different leaching times.

\subsubsection{Comparison of Different Leaching Operations}

The results of direct acid leaching, water leaching-acid leaching, ball milling-acid leaching and ball milling-water leaching-acid leaching are shown in Figure 6. Under the leaching process using $\mathrm{HCl}$ only, the extraction efficiency of $\mathrm{Al}$ increases rapidly in the first $60 \mathrm{~min}$ and then slowly to approximately $22.99 \%$ until $360 \mathrm{~min}$. When the SAD was ground before $\mathrm{HCl}$ leaching, the trend of the extraction efficiency of the $\mathrm{Al}$ of the SAD is in accordance with that with the acid-only leaching. However, the final leaching efficiency reaches $28.42 \%$, which is $5.43 \%$ higher than that of the direct acid leaching. This result indicates that ball milling effectively destroys the complex inlay structure and the pellumina on the surface of metallic metal and simultaneously increases the mechanical activation of the SAD system. By adding the water leaching pretreatment process, the extraction efficiency of 
$\mathrm{Al}$ reaches the highest value of $24.34 \%$ in $60 \mathrm{~min}$ and then remains constant. Although the reaction between water and AlN creates a noncompact structure to increase the extraction efficiency of $\mathrm{Al}$, the particle size of the SAD remains large, and the mechanical activation of the SAD system is low. Thus, water leaching improves the extraction efficiency of Al by only $1.35 \%$. When the two pretreatment operations are added simultaneously, the extraction efficiency of the total $\mathrm{Al}$ peaks at $28.70 \%$ in the acid leaching within a mere $10 \mathrm{~min}$. To reach the similar efficiency of extracting the total $\mathrm{Al}, 240 \mathrm{~min}$ is imperative during ball milling-acid leaching. The lower extraction efficiency of $\mathrm{Al}$ mainly shows the high proportion of the insoluble $\mathrm{Al}$ compounds, including corundum and magnesia-alumina spinel in the SAD. Hence, adding water leaching and ball-milling can not only increase the extraction efficiency of $\mathrm{Al}$ but also significantly accelerate the reaction rate of $\mathrm{Al}$ in the acid leaching procedure.

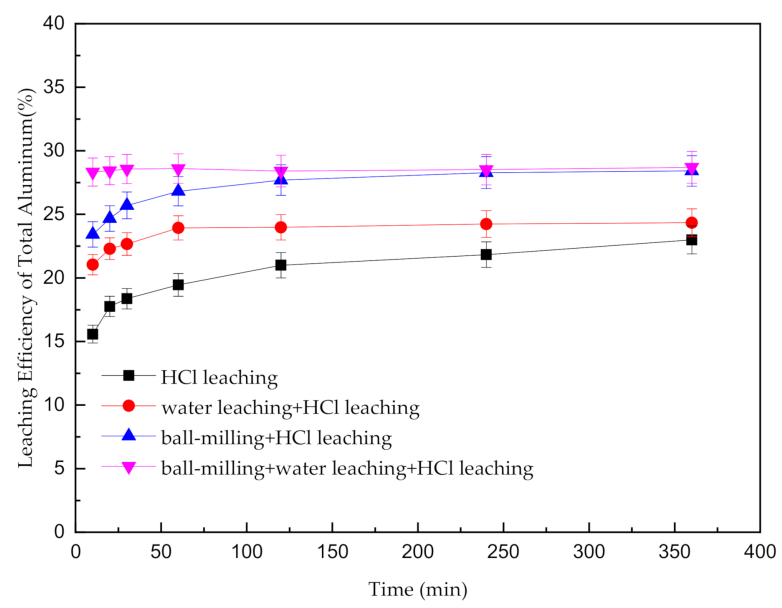

Figure 6. Effect of the different treatments of SAD on the leaching rate of the total Al.

\subsection{Analysis of the Evolution of Phases and Morphology}

The XRD patterns of the SAD under different treatments are shown in Figure 7. As shown in Figure $7 \mathrm{a}$, the ground SAD has similar mineralogical phases compared with the initial SAD, presenting almost the same peak except the attenuation of the $\mathrm{NaCl}$ peak, which is due to the wet grinding operation. After the water leaching operation is added, some changes, including the disappearance of the salt phase, the attenuation of the diffraction intensity of the AlN peaks, and the appearance of the new $\mathrm{Al}(\mathrm{OH})_{3}$ phase, can be observed in Figure $7 \mathrm{~b}$. The majority of the $\mathrm{AlN}$ in the SAD turns to $\mathrm{Al}(\mathrm{OH})_{3}$ by the grinding-water leaching process. Comparison of Figure $7 \mathrm{~b}, \mathrm{c}$ shows that the diffraction intensities of the peaks of corundum $\left(\alpha-\mathrm{Al}_{2} \mathrm{O}_{3}\right)$, diaoyudaoite $\left(\beta-\mathrm{Al}_{2} \mathrm{O}_{3}\right)$, spinel $\left(\mathrm{MgAl}_{2} \mathrm{O}_{4}\right)$, and quartz $\left(\mathrm{SiO}_{2}\right)$ increase, and the phases of $\mathrm{Al}$ and $\mathrm{Al}(\mathrm{OH})_{3}$ disappear with time. $\mathrm{Al}$ and $\mathrm{Al}(\mathrm{OH})_{3}$, which are formed in the reaction between $\mathrm{AlN}$ and water, are decomposed, and the other components are insoluble in $\mathrm{HCl}$. The diffraction intensity of the $\mathrm{Al}_{2} \mathrm{O}_{3}$ peaks remains constant, which can indicate that $\mathrm{Al}_{2} \mathrm{O}_{3}$ just slightly dissolves in $\mathrm{HCl}$. As a result, nearly all metal $\mathrm{Al}, \mathrm{AlN}$, and partial $\mathrm{Al}_{2} \mathrm{O}_{3}$ are leached by the grinding-water leaching-acid leaching process.

Figure 8 shows the microstructures of the SAD after the different treatments. As shown in Figure $8 \mathrm{a}$, the initial SAD has an irregular shape and rugged surface and is covered by many salt granules. Moreover, several components in the SAD are closely linked together, and only partial metallic $\mathrm{Al}$ in the $\mathrm{SAD}$ is exposed. After grinding, Figure $8 \mathrm{~b}$ clearly shows the fracture surface of the $\mathrm{Al}$ metal released from the $\mathrm{Al}$ oxide layers, and the salt granule decreases. These phenomena indicate that the wrapped metallic $\mathrm{Al}$ in the initial SAD is released, and the pellumina is destroyed by ball milling. After the grinding-water leaching operation, the round and nonangular SAD with different particle sizes and some tiny $\mathrm{Al}(\mathrm{OH})_{3}$ particles can be seen in Figure $8 \mathrm{c}$. This result suggests that the salt components on the SAD surface are dissolved completely, and AIN is decomposed and transformed into the $\mathrm{Al}(\mathrm{OH})_{3}$ phase. From Figure 8d, the residual dregs, which mainly include some insoluble 
components, such as corundum and magnesia-alumina spinel in the $\mathrm{HCl}$ solution, show a smooth surface and are smaller than the initial SAD. This phenomenon is verified from the XRD results.

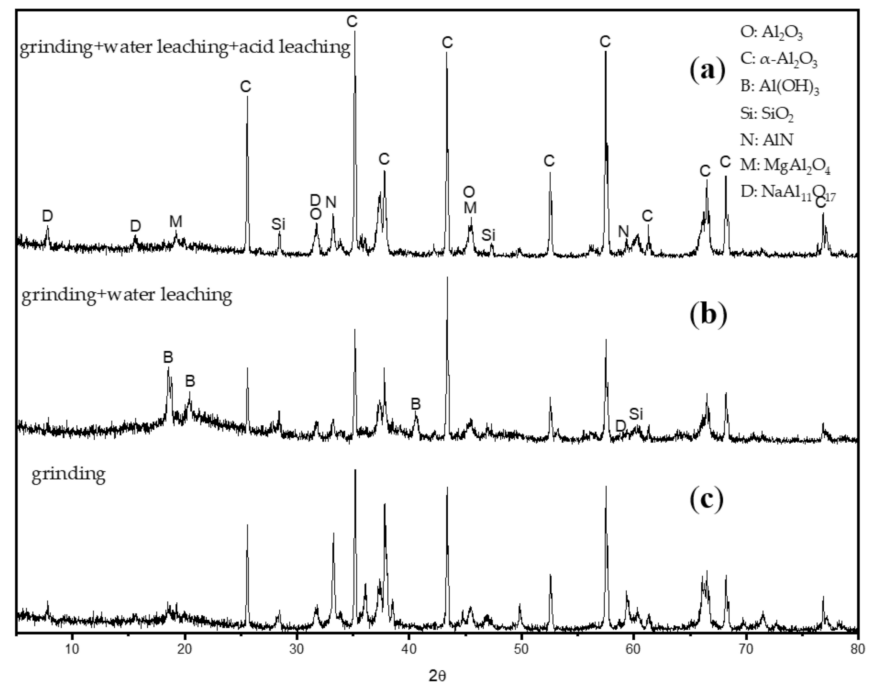

Figure 7. XRD patterns of the SAD after different treatments: (a) after grinding for $2.5 \mathrm{~min}$; (b) after the grinding and water leaching operation; and (c) after the grinding-water leaching-acid leaching operation.
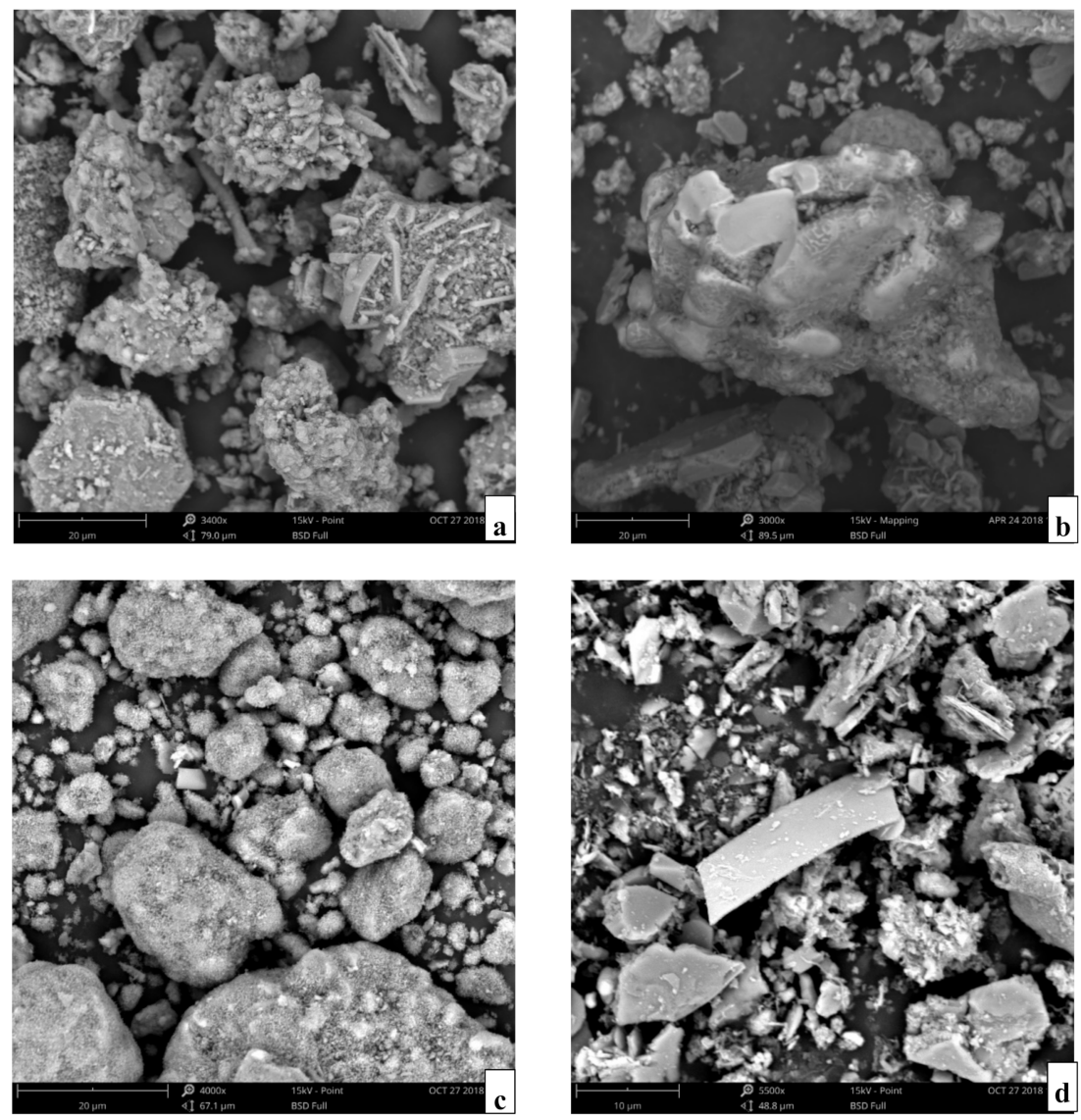

Figure 8. Microstructures of the SAD after different treatments: (a) as received; (b) after grinding for $2.5 \mathrm{~min}$; (c) after the grinding and water leaching operation; and (d) after the grinding-water leaching-acid leaching operation. 


\section{Conclusions}

In this study, grinding and water leaching are potential pretreatment operations to increase the leaching efficiency of the non-refractory $\mathrm{Al}$ components such as metallic $\mathrm{Al}$ and $\mathrm{AlN}$ in the SAD in the subsequent acid leaching operation. The leaching efficiency of $\mathrm{Al}$ was only $22.99 \%$ under the direct acid leaching process. Thus, the process mineralogy of SAD was investigated to observe the complex intertexture and continuous network structure in the SAD. Adding ball milling or water leaching operation resulted in leaching efficiencies of $28.42 \%$ and $24.34 \%$, respectively. Ball milling mainly exposed more metallic $\mathrm{Al}$ and alumina particles and increased the mechanical activation of the SAD system. Water leaching led to the noncompact structure created by the reaction between water and AlN to slightly improve the efficiency of leaching Al. The XRD and SEM results verified the chemical and phase analyses. As a result, pretreatment operations can increase approximately $5.71 \%$ of the $\mathrm{Al}$ leaching efficiency from the SAD in the subsequent acid leaching operation.

Supplementary Materials: The following are available online at http://www.mdpi.com/2227-9717/8/10/1269/s1.

Author Contributions: G.Z. designed the study and participated in the data analysis. H.F. conducted the experiments and wrote the paper. Q.Y., L.X., S.Z. and D.L. participated in the discussion of the results. All authors have read and agreed to the published version of the manuscript.

Funding: This work was supported by the Fundamental Research Funds for the Central Universities of Central South University (Project No. 2018zzts795).

Conflicts of Interest: The authors declare no conflict of interest.

\section{References}

1. Hagelstein, K. Globally sustainable manganese metal production and use. J. Environ. Manag. 2009, 90, 3736-3740. [CrossRef]

2. Green, J.A.S. Aluminum Recycling Processing for Energy Conservation and Sustainability; ASM International: Materials Park, OH, USA, 2007; p. 288.

3. Institute, I.A. Global Aluminium Recycling: A Cornerstone of Sustainable Development; International Aluminium Institute: London, UK, 2009; p. 36.

4. Aluminum Association. Aluminum-The Element of Sustainability; The Aluminum Association: Washington, DC, USA, 2011; p. 70.

5. Mahinroosta, M.; Allahverdi, A. A promising green process for synthesis of high purity activated-alumina nanopowder from secondary aluminum dross. J. Clean. Prod. 2018, 179, 93-102. [CrossRef]

6. Tsakiridis, P.E. Aluminium salt slag characterization and utilization-A review. J. Hazard. Mater. 2012, 217-218, 1-10. [CrossRef]

7. Xiao, Y.P.; Reuter, M.A.; Boin, U. Aluminium recycling and environmental issues of salt slag treatment. J. Environ. Sci. Health Part A 2005, 40, 1861-1875. [CrossRef]

8. Das, B.R.; Dash, B.; Tripathy, B.C.; Bhattacharya, I.N.; Das, S.C. Production of $\eta$-alumina from waste aluminium dross. Miner. Eng. 2007, 20, 252-258. [CrossRef]

9. Calder, G.V.; Timothy, D.S. Aluminum Reactions and Problems in Municipal Solid Waste Landfills. Waste Manag. 2010, 14, 258-265. [CrossRef]

10. Gil, A. Management of the salt cake from secondary aluminum fusion processes. Ind. Eng. Chem. Res. 2005, 44, 8852-8857. [CrossRef]

11. Tenorio, J.A.S.; Espinosa, D.C.R. Effect of salt/oxide interaction on the process of aluminum recycling. J. Light Met. 2002, 2, 89-93. [CrossRef]

12. Gil, A.; Korili, S.A. Management and valorization of aluminum saline slags: Current status and future trends. Chem. Eng. J. 2016, 289, 74-84. [CrossRef]

13. Meshram, A.; Singh, K.K. Recovery of valuable products from hazardous aluminum dross: A review. Resour. Conserv. Recycl. 2018, 130, 95-108. [CrossRef]

14. Peterson, R.D.; Newton, L. Review of aluminum dross processing. In Light Metals 2002; Schneider, W.A., Ed.; John Wiley \& Sons, Inc: San Antonio, TX, USA, 2002; pp. 1029-1037. 
15. Zhang, L. State of the Art in Aluminum Recycling from Aluminum Dross. In Light Metals: Proceedings of Sessions: TMS Annual Meeting; John Wiley \& Sons, Inc.: San Antonio, TX, USA, 2006; pp. 931-936.

16. Hiraki, T.; Nagasaka, T. An easier upgrading process of aluminum dross residue by screening technique. J. Mater. Cycles Waste Manag. 2014, 17, 566-573. [CrossRef]

17. Türk, M.; Altıner, M.; Top, S.; Karaca, S.; Bouchekrit, C. Production of Alpha-Alumina from Black Aluminum Dross Using $\mathrm{NaOH}$ Leaching Followed by Calcination. JOM 2020. [CrossRef]

18. David, E.; Kopac, J. Hydrolysis of aluminum dross material to achieve zero hazardous waste. J. Hazard Mater. 2012, 209-210, 501-509. [CrossRef] [PubMed]

19. Nhi, T.T.N.; Lee, M.S.; Thi Hong, N. Ball Milling Treatment of Black Dross for Selective Dissolution of Alumina in Sodium Hydroxide Leaching. Processes 2018, 6. [CrossRef]

20. Bruckard, W.J.; Woodcock, J.T. Characterisation and treatment of Australian salt cakes by aqueous leaching. Miner. Eng. 2007, 20, 1376-1390. [CrossRef]

21. Tsakiridis, P.E.; Oustadakis, P.; Agatzini-Leonardou, S. Aluminium recovery during black dross hydrothermal treatment. J. Environ. Chem. Eng. 2013, 1, 23-32. [CrossRef]

22. Li, Q.; Yang, Q.; Zhang, G.; Shi, Q. Investigations on the hydrolysis behavior of AlN in the leaching process of secondary aluminum dross. Hydrometallurgy 2018, 182, 121-127. [CrossRef]

23. Yang, Q.; Li, Q.; Zhang, G.; Shi, Q.; Feng, H. Investigation of leaching kinetics of aluminum extraction from secondary aluminum dross with use of hydrochloric acid. Hydrometallurgy 2019, 187, 158-167. [CrossRef]

24. Dash, B.; Das, B.R.; Tripathy, B.C.; Bhattacharya, I.N.; Das, S.C. Acid dissolution of alumina from waste aluminium dross. Hydrometallurgy 2008, 92, 48-53. [CrossRef]

25. Sarker, M.S.R.; Alam, M.Z.; Qadir, M.R.; Gafur, M.A.; Moniruzzaman, M. Extraction and characterization of alumina nanopowders from aluminum dross by acid dissolution process. Int. J. Miner. Metall. Mater. 2015, 22, 429-436. [CrossRef]

26. Nhi, T.T.N.; Song, S.J.; Lee, M.S. Development of a hydrometallurgical process for the recovery of pure alumina from black dross and synthesis of magnesium spinel. J. Mater. Res. Technol. 2020, 9, 2568-2577. [CrossRef]

(C) 2020 by the authors. Licensee MDPI, Basel, Switzerland. This article is an open access article distributed under the terms and conditions of the Creative Commons Attribution (CC BY) license (http://creativecommons.org/licenses/by/4.0/). 